Int. J. Electrochem. Sci., 12 (2017) $770-781$

\title{
The Electrochemical Redox Mechanism and Antioxidant Activity of Oleanolic Acid Based on Multi-walled Carbon Nanotuber Screen-printing Electrode
}

\author{
Hongqiao Yang ${ }^{1,2}$,Xiaoyan $\mathrm{Ma}^{1,2}$, Huabin xiong ${ }^{1,2}$,Jinting Gao ${ }^{1,2}$, Xiaofen $\mathrm{Li}^{1,2}$, Yuntao Gao ${ }^{1,2, *}$, \\ Qian Zhang \\ ${ }^{1}$ The Engineering Laboratory of Polylactic Acid-Based Functional Materials of Yunnan, School of \\ Chemistry and Environment, Yunnan Minzu University, Kunming 650500, China. \\ ${ }^{2}$ Key Laboratory of Comprehensive Utilization of Mineral Resource in Ethnic Regions, Joint Research \\ Centre for International Cross-border Ethnic Regions Biomass Clean Utilization in Yunnan, School of \\ Chemistry \& Environment, Yunnan Minzu University, Kunming, 650500, P. R. China. \\ *E-mail: ymz409@163.com
}

doi: $10.20964 / 2017.01 .17$

Received: 8 August 2016 / Accepted: 4 November 2016 / Published: 12 December 2016

This article emphasis on the application of the multi-walled carbon nanotubes screen printing electrodes(MWCNTs/SPEs) to reseach of plant active constituent (oleanolic acid, OA) by electrochemistry analytic procedure. The work explores the optimization of reaction conditions of OA. The stoichiometric ratio of OA on DPPH about 1:1, electrochemical redox mechanism and antioxidant activity of $\mathrm{OA}$ were obtained by the determination of electrochemical kinetics parameters such as electron transfer numbers $(n)$, propons $(m)$, electron charge coefficient $(\alpha)$, and standard electron transfer rate constant $\left(k_{s}\right)$ are $1,1,0.66,0.53$ respectively based on electrochemical behavior at MWCNTs/SPEs. This method is fast, convenient, low-cost, practicable and can be used to the trace amount determination of the content of triterpenes in natural product.

Keywords: Screen-printed electrodes; Oleanolic acid; Electrochemical redox mechanism; Antioxidant activity;

\section{FULL TEXT}

(C) 2017 The Authors. Published by ESG (www.electrochemsci.org). This article is an open access article distributed under the terms and conditions of the Creative Commons Attribution license (http://creativecommons.org/licenses/by/4.0/). 